\title{
Saúde e serviços assistenciais na experiência de jovens Guarani da comunidade Boa Vista*
}

\section{Health and social services in the Guarani young persons experiences of Boa Vista community}

\author{
Maria Daniela Corrêa Macedo ${ }^{1}$, Denise Dias Barros ${ }^{2}$
}

MACEDO, M. D. C.; BARROS, D. D. Saúde e serviços assistenciais na experiência de jovens Guarani da comunidade Boa Vista. Rev. Ter. Ocup. Univ. São Paulo, v. 21, n. 3, p. 182-188, set./ dez. 2010.

\begin{abstract}
RESUMO: E entre modos de vida e a percepção dos processos de saúde/doença ancorados em seu contexto, o artigo propõe apreender a maneira como os jovens da comunidade Guarani de Boa Vista (Ubatuba, SP) percebem e se relacionam com a atenção à saúde que se inscreve em suas vidas e na dinâmica de suas comunidades. Estudo de caso realizado com quatro jovens adultos Guarani-Mbyá, com idade entre 13 e 29 anos, por meio de entrevistas abertas, gravadas, transcritas e textualizadas entre 2007 e 2009 . As histórias de vida evidenciaram a importância da saúde como um dos espaços de mediação cultural entre as dinâmicas urbanas e aquelas constituídas na aldeia. $\mathrm{O}$ modo de vida na aldeia - com seus valores, mitos, processos rituais e concepção de relações entre os seres - ancoram-se em um conjunto de saberes que são conflitantes e concorrentes aos saberes técnico-científicos vinculados à saúde, mas complementam em diferentes momentos ou situações. Indaga-se sobre as condições de coabitação de tais saberes e sobre os contornos do diálogo que se estabelece nos serviços de saúde - na percepção dos jovens - entre culturas tanto singularmente como coletivamente. Nota-se a coexistência de dois mundos de lógicas diferenciadas de concepção de saúde e a necessidade do diálogo entre as diferentes concepções. Observou-se forte presença do uso das terapêuticas Guarani (ervas, banhos, dietas, pajelanças e/ou ritos de iniciação), em associação com terapêuticas e procedimentos propostos pelo Sistema Único de Saúde (SUS).
\end{abstract}

DESCRITORES: Saúde indígena; Atenção primária à saúde; Ação intersetorial; População indígena.

\footnotetext{
*Discussão do artigo integra a dissertação: Jovens entre culturas:itinerários e perspectivas de jovens Guarani entre a aldeia Boa Vista e a cidade de Ubatuba.

1. Terapeuta Ocupacional. Mestre em Ciências pela Faculdade de Medicina da USP. E-mail: mariadaniela@usp.br

2. Doutora em Sociologia. Departamento de Fisioterapia, Fonoaudiologia e Terapia Ocupacional da Faculdade de Medicina USP. Contato: ddbarros@usp.br

Endereço para correspondência: Maria Daniela Corrêa de Macedo R: Nazarenos, 60- Centro Ubatuba/ SP CEP: 11.680-000. e-mail: mariadaniela@usp.br
} 


\section{INTRODUÇÃO}

$\mathrm{O}$ s Guarani representam hoje a maior população entre as sociedades ameríndias em terras brasileiras. Segundo o Instituto Socioambiental, são cerca de 34 mil pessoas distribuídas por Rio Grande do Sul, Santa Catarina, Paraná, São Paulo, Rio de Janeiro e Mato Grosso do Sul: 18 a 20 mil Kayowá, 8 a 10 mil Ñandeva e 5 a 6 mil Mbyá, grupo historicamente localizado nas Regiões Sudeste e Sul do Brasil. Os subgrupos Guarani exibem diferenças linguísticas, nas práticas rituais, nos costumes, assim como na organização política e religiosa (ISA). No município de Ubatuba (SP) situa-se a comunidade Guarani de Boa Vista com qual trabalhamos, formada pelo subgrupo Mbyá e aglutinando cerca de 130 pessoas. Os jovens desta comunidade estão inseridos em atividades relacionadas principalmente com o artesanato, a coleta de palmito e com a educação formal.

Há vasta literatura sobre os Guarani no que diz respeito à religião e às relações sociais, políticas e econômicas. Os enfoques sobre a juventude são principalmente relacionados a questões ambientais (demarcação de terras, recursos naturais) encontrados em Ladeira (1984), Almeida (2001), emocionais/biológicas (suicídio, alcoolismo) em Tardivo (2005), Meihy (1991, Morgado (1991) e Souza e Garnelo (2006), fisiológicas (ciclo vigília/sono, reprodução) em Azevedo e Adorno (2007), religiosas (rituais de nominação) em Chamorro Arguello (1998), educacionais (pedagogias, gramática) em Meliá (1997), Ferreira (2002), Godoy (2007) e sociais (como os rituais de passagem) em Rangel (1999) e Alcântara (2007). Entretanto, constatamos que são poucas as pesquisas referentes aos jovens e não encontramos estudos específicos sobre os jovens da comunidade Boa Vista.

O recorte que utilizamos para definir o grupo com o qual trabalhamos - pessoas de 13 a 29 anos - representa em nosso estudo os jovens que fizeram os ritos de iniciação ou os estão vivenciando o rito, não sendo, portanto, considerados pela comunidade como pertencentes ao grupo das crianças. Optamos entrevistar os jovens da Boa Vista pois são os interlocutores desta comunidade Guarani, realizam o papel de mediadores interculturais, muitos deles estão no ensino formal e são intérpretes do guarani/ português e desenvolvem diversas atividades de prestígio social na comunidade. Abramo e León (2005) afirmam que existe no Brasil a tendência, baseada em critérios estabelecidos pelas Nações Unidas e por instituições como o IBGE, de definir como jovem as pessoas entre os 15 e os 24 anos. Enfatizando, no entanto, a existência de profunda variação de acordo com as situações sociais e segundo as trajetórias pessoais.
Entre os Guarani - conforme aponta a literatura e nossa experiência de campo - a vida social, as noções de saúde e a religiosidade estão profundamente interligadas. A religiosidade constitui o centro da organização social, e as práticas de cura e o saber a estas vinculadas não se dissociam. Schaden (1989) explica que os Guarani identificam respectivamente Nyandererykeý e Tyvýry, filhos de Nyanderuvusú, como "nosso pai grande" e Nyanderú Mbaekuaá como "nosso pai conhecedor de todas as coisas". O autor afirma que o mito garante as representações religiosas fundamentais e o próprio destino, mantendo correlação com práticas históricas, como as danças medicinais trazidas por Nyandereykeý(SCHADEN, 1989, p.124), que integram ritos de nominação nos quais o chefe religioso descobre o nome correspondente à alma da pessoa. A autoridade religiosa corresponde historicamente a uma liderança política da comunidade. Os Mbyá, ainda segundo Schaden (1962), não permitem casamentos com pessoas não Guarani, pois estas não sabem rezar, isto é, não podem participar satisfatoriamente das cerimônias religiosas: "Só Guarani de verdade é que reza" (SCHADEN, 1962, p.30). A autoridade, antes ligada ao líder religioso, está enfraquecida, e o poder deve ser dividido com outras lideranças (deslocamento da sacralização do poder). Para Schaden (1962), o ideal de cultura e vida, fator de coesão da comunidade, perde sua força mítica, e se percebe uma dissolução do grupo.

As pesquisas de Chamorro Argüello (1998) voltamse para as relações entre saúde e o universo do sagrado. A autora estuda o rito de nominação Nimongaraí, antecedido por longo processo do qual faz parte a terapia de cura, danças e a recepção dos nomes. Estes momentos observados podem se repetir ou coexistir; todos são embalados pelo som de violão, violinos e outros instrumentos. Observam-se, dentro da casa de reza, o altar ( $a m b a)$ e a importância do uso do cachimbo (petÿngua) e da fumaça. Quanto à terapia de cura, são centrais no processo ritual a fumaça e a massagem, em que o rezador solta a fumaça sobre o paciente e a inspira novamente, em coordenação com movimentos parecidos com o da tapotagem (leves pancadas com a mão em concha sobre todo o corpo). A relação entre saúde e religiosidade não se dissociam, sendo os processos de cura realizados tanto nas cerimônias de nominação quanto em outros momentos rituais.

Num processo de coabitação e convivência com o mundo das casas de reza, foram sendo instituídos os serviços de saúde ligados ao Estado brasileiro. Pensar em saúde no universo Guarani, atualmente, implica discutir seu conceito, suas significações, simbologias e concepções, como as relações entre os serviços instituídos na aldeia e os 
serviços da cidade. As relações são estabelecidas, segundo Augé (1997), no paradoxo da contemporaneidade com a diversidade do mundo que se recompõe a cada instante. Trata-se, portanto, da discussão dos mundos, da cidade/ aldeia e não do mundo, ainda que estes se comuniquem entre si, cada qual com pelo menos uma imagem do outro, momento este da crise de identidade/alteridade. Percebemos que, neste momento, a saúde encontra-se como intersecção de dois mundos; é principalmente na figura dos agentes de saúde que se evidencia a crise de identidade entre os conhecimentos Guarani de saúde e os técnico-científicos. A necessidade de diálogo é constante para a composição de saberes dos agentes, no entanto numa relação de poder, entre o saber da comunidade e o médico/científico. Evidencia-se, assim, a importância de estudos ligados à saúde indígena e à juventude Guarani, como os trabalhos já referidos sobre álcool, suicídio, violência e maternidade, entre outros.

A comunidade Guarani de Boa Vista convive com serviços públicos que marcam a presença do Estado brasileiro e formam espaços de intersecção entre práticas culturais diferenciadas. Além da Fundação Nacional do Índio (FUNAI) fundada em 1967, as instituições educacionais e de saúde somam-se às entidades religiosas e não governamentais.

Há na aldeia um posto de saúde e uma casa onde reside a auxiliar de enfermagem que há 15 anos é responsável pela prestação de primeiros socorros à população. $\mathrm{O}$ posto foi criado em 1985, com a organização e a luta pela demarcação de terra, e o trabalho era realizado pela Funai. Em 1999, a Fundação Nacional da Saúde (FUNASA), do Ministério da Saúde, assumiu toda a responsabilidade com a saúde indígena. A contratação da equipe de saúde tornar-se-ia possível a partir de convênio com o Projeto Rondon. Vale destacar que, segundo Gonçalves (2007), a partir da implantação pela Funasa dos Distritos Sanitários Especiais Indígenas (DSEIs), em 1999, passou-se a dar mais importância a questões de saúde indígena.

Atualmente, a equipe do posto inclui médico, dentista, enfermeira e agente de saúde Guarani. Há quatro salas destinadas à farmácia, ao atendimento médico, ao atendimento odontológico e ao arquivo. $\mathrm{Na}$ varanda do posto, as pessoas aguardam o atendimento. Os agentes de saúde, de odontologia e de saneamento (funcionários da Funasa) são de Boa Vista.

Trataremos, neste artigo, de discutir a percepção dos jovens sobre a saúde, que gera e favorece mediação cultural entre cidade e aldeia e entre modos de vida e percepções dos processos de saúde/doença. Buscamos, ainda, apreender as tensões e negociações que se colocam nas relações estabelecidas entre as práticas Guarani e as propostas do serviço de saúde sob responsabilidade da Funasa.

\section{PROCEDIMENTOS METODOLÓGICOS}

Trata-se de trabalho qualitativo realizado com apoio em observação e entrevistas, precedido de longo período de construção de relações e aproximação com a comunidade. Ainda que não se configure como trabalho etnográfico, a etnologia forneceu as bases para o desenvolvimento desta pesquisa de campo e das interpretações desenvolvidas. Foram realizadas entrevistas abertas, a partir de roteiro de orientação temático e observações em campo de 2007 à 2009 para construção das análises. Na definição de colaboradores, respeitamos as seguintes condições: ser considerado/a pela comunidade como membro Guarani, ser residente da aldeia Boa Vista no momento do estudo e ter entre 13 e 29 anos. Ademais, o/a colaborador/a deveria participar ao menos de um destes tipos de atividades: ensino formal (estudante ou professor); grupo de artesanato; e/ou grupo de coleta do palmito (produção coletiva).

As pessoas foram convidadas a participar do estudo, respeitando-se os preceitos da legislação vigente para a realização de pesquisa com seres humanos. Para os menores de 18 anos, obtivemos a concordância de pais ou responsáveis. (Processo no 1168/07 Comissão de Ética para Análise de Projetos de Pesquisa - CAPPesq aprovado em 20/2/2008 e Protocolo Funai n ${ }^{\circ}$ 0595/07 aprovado em 22/7/2008).

A construção dos dados empíricos deu-se por meio de cinco encontros (com duração de cerca de uma hora) com cada um dos jovens, respeitando-se a escolha do colaborador quanto a local e horário para a concessão da entrevista. $\mathrm{O}$ tratamento dos registros orais das entrevistas seguiu a metodologia utilizada pelo Núcleo de Estudos em História Oral (NEHO) da USP. Após a transcrição (passagem do oral para o código escrito das palavras ditas ainda em estado bruto), foi feita a textualização, em que se eliminam as perguntas e alguns erros gramaticais, e foram retiradas as palavras sem peso semântico e sons e ruídos, em favor de um texto mais claro (MEIHY, 2005).

A análise das entrevistas foi realizada em duas etapas. Após a transcrição da entrevista, os relatos foram categorizados em eixos temáticos e foi realizada uma conversa com o colaborador sobre a entrevista textualizada, para conferir a validade e a fidedignidade desta e produzir informações complementares. Em seguida, produziu-se um texto em que se articulam o material empírico (entrevistas e observação em campo) e os conhecimentos teóricos. O diálogo constante entre pesquisador e colaborador foi imprescindível para a análise dos dados. Buscou-se dar 
visibilidade acadêmica ao conhecimento Guarani, sem descaracterizá-lo e descontextualizá-lo.

\section{DISCUSSÃO DOS RESULTADOS: JOVENS E CONCEPÇÃO DE SAÚDE}

Nos relatos e na observação em campo, surgiram duas questões principais sobre saúde e os Guarani: a relação da concepção de saúde vinculada a questões religiosas; e a relação dos jovens com os serviços de saúde, dentro e fora da aldeia.

As relações com a religiosidade são muito presentes nas sociedades originárias do território brasileiro. Ainda que cada uma tenha desenvolvido um sistema cultural particular, é possível, segundo os estudiosos, apontar como princípio geral que o processo saúde/doença transcorre dentro de uma ordem cosmológica a qual abarca forças da natureza, forças invisíveis e forças sociais e humanas (GONÇALVES, 2007, p.14).

Frequentemente, os Guarani procuram antes a cura ritual, familiar ou orientada pelo chefe religioso, para depois recorrer ao serviço de saúde. Afirmam que esta dinâmica tem se modificado em algumas famílias. Os agentes de saúde respeitam as práticas individuais.

"Porque agora mudou um pouco, algumas famílias pensam diferente: vai levar para o médico, que o médico resolve. Alguns não, alguns procuram o pajé. Assim, depende da família, porque não adianta a gente chegar e dizer 'Tem que levar para o pajé', porque, às vezes, o pessoal não entende (...) O que a gente faz é o que é melhor para família. Eu acho que a maioria estão procurando o pajé, por enquanto, mas não sei até quando mais" (José, colaborador)

As relações entre as concepções de saúde e a religiosidade, no entanto, parecem sofrer modificações na prática atual, e o agente de saúde realiza em diversos momentos o diálogo e as correlações entre o conhecimento técnico-científico, representado pela equipe de saúde, e o de saúde Guarani, representado pelas lideranças religiosas e comunidade.

Observamos que os jovens concebem a saúde, os serviços e os cuidados medicamentosos como antes não pertencentes à cultura, embora componentes de uma nova concepção que se inscreve igualmente em suas vidas e no projeto de suas comunidades. No contexto atual de profunda transformação social, a possibilidade da educação formal parece ser considerada como fundamental. Kerexu, uma de nossas colaboradoras, enfatiza a importância do bilinguismo, ou seja, do domínio do português, mesmo para trabalhar na aldeia:
“(...) as duas línguas são importantes: uma é para comunicação e outra porque faz parte da cultura - tem que manter da cultura - e outra é para comunicação. A escola, a saúde que não faziam parte da cultura; a partir de agora, quem se formar vai se formar pra ser um doutor, um professor, uma dentista, por exemplo, para trabalhar na aldeia. Tem que entender português e que entender a cultura também, acho importante (...)." (Kerexu, colaboradora)

José acrescenta:

“(...) penso pro futuro na aldeia ter mais pessoas estudando, ter como fazer um curso de medicina ou outras coisas, ser o próprio índio a trabalhar na aldeia (...)." (José, colaborador)

Os jovens entrevistados parecem considerar os serviços de saúde como importantes na coexistência com o modo de vida Guarani para compor novos projetos. Destacam as práticas e os serviços de saúde, mesmo que não pertencendo à sua cultura, como algo já integrado ao dia a dia, embora seja necessário criar estratégias para melhorar sua dinâmica e funcionamento. As críticas recaem, principalmente, sobre o transporte de pacientes e consultas até hospitais distantes.

"Para o futuro espero que mude mais um pouquinho a aldeia (...) Como a estrada, de chegar até lá na aldeia (...) abre a estrada até a aldeia. Seria melhor pra todos nós (...) O carro vai descer lá (...) Por exemplo, o carro da Funasa vai até lá buscar o paciente." (Madalena, colaboradora)

Os jovens enfatizam o desejo da intermediação entre os saberes e da interlocução, realizada, no momento, principalmente pelos jovens que transitam pelo mundo da cidade e da aldeia.

Em seu relato, o jovem José explicitou a composição e as formas de interação, intersecção e negociação social que se realizam entre concepções, práticas, sentidos e saberes distintos. O diálogo torna-se essencial para este processo. Ao discorrer sobre sua experiência como agente de saúde e a situação fronteira de seu trabalho - que espelha a visão da sociedade nacional - e de sua comunidade, foi enfático:

\footnotetext{
"Quatro anos como agente (...). Porque antes, de não ter isso, um funcionário indígena, era mais dificil; tem gente, mulheres, homens com mais dificuldade de falar (...). A gente, que estudou um pouquinho, a gente sabe falar, explicar pro paciente; então, a gente é contratado e orienta o paciente, o mais idoso que não fala, a gente tem que falar em Guarani. Hoje, o agente é um facilitador para chegar orientação de saúde. É que é dificil, a gente é contratado pra fazer isso, então, a gente tem que fazer as orientações. Você vê que primeiro a gente procura o pajé,
} 
que é o curandeiro, depois a gente procura o médico. Até as crianças. Eu acho, no meu modo, no meu ponto de vista, está indo bem, porque tem as doenças, tipo pneumonia; isso, o curandeiro, ele não sabe qual é a erva que cura o tipo da pneumonia, mas o médico sabe o que é isso, e tem coisa que médico não sabe, mas o curandeiro sabe; tem que seguir os dois caminhos. Primeiro era dificil o diálogo; agora está melhor (...) porque a gente, como eu, já fala um pouco mais em português também (...) Sim, a questão da língua é importante pro trabalho." (José, colaborador)

Neste local fronteiriço e de intersecção, o papel de intermediação foi evocado diversas vezes como parte do trabalho do agente de saúde.

\begin{abstract}
"Eu acho importante a função do agente de saúde, porque ajuda um pouco a comunidade... que nem as crianças, às vezes, faz acompanhamento; a gente acompanha o paciente quando vai para cidade ou São Paulo. Dificilmente o Guarani entende [o português]. Entender é difícil, tem algumas palavras que são mais complicadas. Então, a maioria dos Guarani aqui da aldeia só entende palavras simples, por exemplo, água, sabe pedir se está com fome, pode saber falar, mas o que está sentindo, de sintomas, aonde que sente, é dificil de explicar; qual dor, como que está, como é que a criança está comendo? Então, nessa parte, é importante o agente de saúde porque ajuda." (José, colaborador)
\end{abstract}

Gonçalves (2007), em trabalho sobre a intermediação entre culturas, afirma que o Ministério da Saúde vem se esforçando para estruturar um subsistema diferenciado de atenção de saúde indígena. No entanto, entende que este deva ser integrado ao SUS, com participação comunitária e respeitando-se as especificidades de cada sociedade e sistema cultural.

Atestamos que a relação dos jovens com os serviços na cidade é facilitada quando o agente se coloca no papel de intermediador entre as pessoas da comunidade e os serviços.

Sobre a impessoalidade dos tratamentos na cidade, alguns dos procedimentos, especificadamente no hospital, foram criticados por Kerexu:

"A diferença que achei [no parto] é que aqui na aldeia tem mais cuidado (...) Por exemplo, aqui na aldeia, na hora de ganhar o neném, a mãe não se move mais, fica ali para esperar. Agora, na cidade, tem o lugar onde ganha neném e tem o pré-parto; quando chega a hora, a hora mesmo de nascer, tinha que sair da cama do pré-parto e ir para outra cama, para ganhar o neném. Isso para mim foi um pouco mais dificil..." (Kerexu, colaboradora)

Outra questão apontada como problemática foi a relação com a equipe de saúde que atua na comunidade, sobretudo as formas de tratamento destinadas às pessoas que necessitam de maior qualidade na escuta e compreensão das diferenças culturais. Ainda ocorrem abusos de poder, enfatiza Mário:

“(...) Porque a própria equipe se acostumou com o indígena, quando não acha que não está certo, enfermeira ou equipe, fala com palavrão, parece briga; só que os indios não falam, então, se acostumam com isso também (...). Só que a Marinalva já reagiu, deu o troco, e até a enfermeira acha que ela é brava. Mas quem não vai responder? Todo mundo tem o direito de se defender, acho que eu também; você acostuma mal, porque que as indias não falam, porque até os indios não respondem, têm dificuldade de responder. Acho que para isso deveria a própria equipe (...) ser bem profissional; não é qualquer pessoa que deveria ir à aldeia para trabalhar. Porque o juruá [branco], está certo que é inteligente e formado como enfermeiro, doutor. Mas tem que ser bem profissional (...) é difícil, não só aqui (...) em geral." (Mário, colaborador)

Nesse desafio do diálogo para a composição de um serviço de saúde melhor, os jovens sugeriram que haja maior coerência da parte dos profissionais e que sejam abertos ao entendimento. Sobre sua experiência com a equipe de profissionais, Mario ressaltou:

“(...) a maioria das pessoas não sabem, não procuram entender o que a gente quer falar, o que a gente fala; por isso, o pessoal que trabalha com Guarani tem que ser bem profissional e entender um pouco de psicologia." (Mario, colaborador)

\section{CONSIDERAÇÕES FINAIS}

A fronteira entre a instituição de saúde e a comunidade move-se tanto para dentro, com a moradia e presença permanente da auxiliar de enfermagem e dos atendimentos domiciliares, como para fora da comunidade. A contratação de membros da comunidade Guarani como agentes de saúde, agentes sanitários e auxiliares odontológicos, introduziu campos de permeabilidade e de constante produção de intersecção, com negociações e conflitos, entre a comunidade indígena, a cidade e os serviços na aldeia (as instituições do Estado brasileiro). Ou seja: a saúde torna-se área de intersecção entre mundos.

As ações e a presença da equipe de saúde no território Guarani formam um ambiente importante, em que modos de vida e compreensão de mundo se veem diante de um diálogo necessário. Novos conhecimentos e valores estão sendo apreendidos no âmbito das práticas de saúde, na dinâmica do trabalho dos agentes de saúde Guarani e, igualmente, nas 
idas e vindas entre a aldeia e hospitais e clínicas. Na relação com os dois mundos, os jovens são os que mais sofrem com este momento de encontros culturais, nos quais estão compondo suas próprias concepções em saúde.

No entanto, desde agosto de 2008, está em tramitação o Projeto de Lei 3.958, que altera a Lei 10.683/2003, dispõe sobre a organização da Presidência da República e dos Ministérios e cria a Secretaria de Atenção Primária e Promoção da Saúde, à qual estará vinculada a saúde indígena. Tal projeto propõe a transferência das competências e atribuições exercidas pela Funasa para essa Secretaria. Ainda em discussão, o projeto pode acarretar mudanças nas relações e na prestação dos serviços às comunidades, devido à descentralização da saúde, possibilitando talvez maior independência regional. Hoje, as comunidades criticam o projeto por não fazerem parte da formulação da nova secretaria e a FUNASA está fragilizada por perder sua área de atuação em saúde indígena.

Nos relatos colhidos, foi possível perceber a disposição dos jovens Guarani para integrar saberes e a percepção de que há grande necessidade do diálogo intercultural para melhorar a atenção oferecida pelos serviços de saúde. Mesmo assim, a coexistência e a coabitação de práticas e lógicas diferenciadas constituem ainda importante desafio, tanto para os Guarani, quanto para os profissionais de saúde, principalmente neste momento de alterações legais e da organização dos serviços de saúde.

MACEDO, M. D. C.; BARROS, D. D. Health and social services in the Guarani young persons experiences of Boa Vista community. Rev. Ter. Ocup. Univ. São Paulo, v. 21, n. 3, p. 182-188, set./dez. 2010.

\begin{abstract}
As between modes of life and the perception of the processes of health/disease anchored in their context, this article compels to present how the young in the Guarani indigenous community of Boa Vista in Ubatuba/SP, notices and gives great attention to health services embedded in their lives and in their community dynamics. The qualitative research and case study accomplished including the participation of four 13 to 29 years old Guarani-Mbyá youngsters, were openly submitted to interviews. Recorded and subsequently transcribed into texts, between 2007 and 2009. Histories of life evidenced the importance of health as cultural mediation space between a city and a village and it's way of life also the perception of health and disease processes. The way of life in the village, its values, myths, ritual processes and conception of relationship among beings - constitutes a context based knowledge, which sometimes conflict with the technicalscientific knowledge, seeing it's complements of life in different aspects. The article questions the conditions of cohabitation of such knowledge also the outlines of dialog that it life establishes in the area of health services and the perception of the young within cultures, both uniquely being collective, denoting the coexistence of two worlds of logical differentiated conception in health. Dialogue among different culture and it's concepts is essential. Therefore, the relevant challenge is to value the integration of knowledge and dialog among cultures for the improvement of our health services and its practical association. Strong presence in the use of Guarani therapeutics such as baths, herbs, diets, pajelanças and/or rites initiation were also observed in association with therapeutics and procedures proposed by the General Health System (SUS).
\end{abstract}

KEY WORDS: Primary health care; Indigenous health; Indigenous populations; Intersectional action.

\section{REFERÊNCIAS}

ABRAMO, H.; LEÓN, O.; FREITAS, M. V. (Org.). Juventude e adolescência no Brasil: referências conceituais. São Paulo: Ação Educativa, 2005.

ALCÂNTARA, M. L. B. Jovens indígenas e lugares de pertencimento: análise dos jovens indígenas da Reserva de Dourados/MS. São Paulo: Instituto de Psicologia da Universidade de São Paulo/Laboratório de Estudos do Imaginário, 2007.
ALMEIDA, R. F. T. Do desenvolvimento comunitário a mobilização política: o Projeto Kaiowa-Ñandeva como experiência antropológica. Rio de Janeiro: Contra Capa, 2001.

AZEVEDO, M. A. P.; ADORNO, R. C. F. Juventude e reprodução entre os Guarani-Mbyá da aldeia Morro da Saudade na periferia da cidade de São Paulo. Rev. Bras. Crescimento Desenvolv. Hum., v. 17, n. 2, p. 64-73, 2007 [Citado 12 jun. 2008]. 
Disponível em: http://pepsic.bvs-psi.org.br/scielo.php?script=sci_ arttext\&pid=S0104-12822007000200009\&lng=pt\&nrm=iso.

AUGÉ, M. Por uma antropologia dos mundos contemporâneos. Paris: Bertrand Brasil, 1997.

CHAMORRO ARGUELLO, C. G. O rito de nominação numa aldeia Mbyá-Guarani do Paraná. Diálogos, v. 2, n. 2, p. 201-215, 1998.

FERREIRA, L. O. Antropologia, história e educação: a questão indígena e a escola. Horiz. Antropol., v. 8, n. 18, p. 307-310, 2002 [Citado em out. 2008]. Disponível em: http://www.scielo. br/scielo.php?script $=$ sci_arttext\&pid=S0104-718320020002000 $15 \& \operatorname{lng}=$ pt\&nrm $=$ iso\&tlng $=$ pt.

GODOY, M. G. G. Diálogos interculturais: a educação escolar indígena e as tradições Guarani Mbya. In: Encontro de Estudos Multidisciplinares em Cultura (Enecult), 3., 23-25 maio 2007; Salvador (BA). Anais. Salvador: Faculdade de Comunicação da Universidade Federal da Bahia, 2007 [citado em ago. 2008]. Disponível em: http://www.cult.ufba.br/enecult2007/ MariliaGGhizziGodoy.pdf.

GONÇALVES, L. J. M. Entre culturas: uma experiência de intermediação em saúde indígena [dissertação]. São Paulo: Universidade de São Paulo, Faculdade de Saúde Pública, 2007.

INSTITUTO SOCIOAMBIENTAL (ISA). Povos indígenas no Brasil [Citado em out. 2003]. Disponível em: http://www. socioambiental.org/prg/pib.shtm.

LADEIRA, M. I. Aldeias livres Guarani do litoral de São Paulo e da periferia da capital. In: MONTEIRO, J. M., et al. (Orgs.) Índios no estado de São Paulo: resistência e transfiguração. São Paulo: Yankatu/CPI, 1984. p. 123-144.

MEIHY, J. C. S. B. Canto de morte Kayowá: história oral de vida. São Paulo: Loyola, 1991.

MEIHY, J. C. S. B. Manual de história oral. 5a ed. São Paulo: Edições Loyola, 2005.

MELIÁ, B. Bilingüismo e escrita. In: D’ANGELIS, W.; VEIGA,
J. (Orgs.). Leitura e escrita em escolas indígenas. Campinas: ALB/Mercado de Letras, 1997. p. 89-104.

MORGADO, A. F. Epidemia de suicídio entre os GuaraniKaiowá: indagando suas causas e avançando a hipótese do recuo impossível. Cad. Saúde Pública., v. 7, n.4, p. 585-598, out./dez. 1991 [Citado 16 fev 2009]. Disponível em: http://www.scielo. br/scielo.php?pid=S0102-311X1991000400009\&script=sci arttext\&tlng=pt.

PROJETO DE LEI 3.958/2008 (Altera a Lei ${ }^{\circ} 10.683$, de 28 de maio de 2003, que dispõe sobre a organização da Presidência da República e dos Ministérios, cria secretaria na estrutura do Ministério da Saúde e cria cargos em comissão do Grupo-Direção e Assessoramento Superiores, destinados ao Ministério da Saúde) [Citado em 29 ago. 2008]. Disponível em: http://www.camara.gov. br/sileg/integras/595198.pdf.

RANGEL, L. H. Da infância ao amadurecimento: uma reflexão sobre rituais de iniciação. Interface Comun. Saúde Educ., v. 3, n. 5 , p. $148,1999$.

SCHADEN, E. Aspectos fundamentais da cultura Guarani. São Paulo: EPU/Edusp, 1962.

SCHADEN, E. A mitologia heróica de tribos indígenas do Brasil. 3a ed. São Paulo: Edusp, 1989.

SOUZA, M. L. P.; GARNELO, L. Desconstruindo o alcoolismo: notas a partir da construção do objeto de pesquisa no contexto indígena. Rev. Latinoam. Psicopatol. Fundam., v. 9, n.2, p. 279292, jun. 2006 [Citado 16 fev. 2009]. Disponível em: http://www. fundamentalpsychopathology.org/art/v09_02/06.pdf.

TARDIVO, L. S. P. C. O encontro com o jovem em São Gabriel da Cachoeira: em busca de uma clínica diferenciada. In: SIMPÓSIO INTERNACIONAL DO ADOLESCENTE, 1., São Paulo, 2005. São Paulo: Faculdade de Educação da Universidade de São Paulo; 2005 [Citado em 16 fev. 2009]. Disponível em: http://www. proceedings.scielo.br/scielo.php?script $=$ sci_arttext\&pid $=\mathrm{MSC} 0$ $000000082005000100031 \& \operatorname{lng}=\mathrm{en} \& n r m=\mathrm{ab}$ $\& \operatorname{tng}=$ pt. 